\title{
Yeast product supplementation modulated humoral and mucosal immunity and uterine inflammatory signals in transition dairy cows
}

\author{
K. Yuan, ${ }^{*}$ L. G. D. Mendonça, ${ }^{*}$ L. E. Hulbert, ${ }^{*}$ L. K. Mamedova, ${ }^{*}$ M. B. Muckey, ${ }^{*}$ Y. Shen, ${ }^{*}$ C. C. Elrod, $\dagger$ \\ and B. J. Bradford*1 \\ ${ }^{*}$ Department of Animal Sciences and Industry, Kansas State University, Manhattan 66506 \\ †Vi-COR Inc., Mason City, IA 50402
}

\begin{abstract}
The transition from late gestation to early lactation is characterized by substantial metabolic stress and altered immune function. The objective of this study was to assess the effects of supplementing a yeast product derived from Saccharomyces cerevisiae on immunity and uterine inflammation in transition cows. Forty multiparous Holstein cows were blocked by expected parturition date and randomly assigned within block to 1 of 4 treatments $(\mathrm{n}=10)$ from $21 \mathrm{~d}$ before expected parturition to $42 \mathrm{~d}$ postpartum. Rations were topdressed with a product containing yeast culture plus enzymatically hydrolyzed yeast (YC-EHY; Celmanax, Vi-COR, Mason City, IA) at the rate of $0,30,60$, or $90 \mathrm{~g} / \mathrm{d}$ throughout the experiment. Cows were injected subcutaneously with ovalbumin on $\mathrm{d}-21,-7$, and 14 to assess their humoral response. Data were analyzed using mixed models with repeated measures over time. Concentrations of colostrum IgG were unaffected by treatments. A treatment $\times$ week interaction was observed for somatic cell linear score, reflecting a tendency for a quadratic dose effect on wk $1(2.34,2.85,1.47$, and $4.06 \pm 0.59$ for $0,30,60$, and $90 \mathrm{~g} / \mathrm{d}$, respectively) and a quadratic dose effect on wk $5(1.36,-0.15,-1.07$, and $0.35 \pm 0.64$ for $0,30,60$, and $90 \mathrm{~g} / \mathrm{d}$, respectively). Platelet count was increased by YC-EHY. Increasing YC-EHY dose linearly increased plasma anti-ovalbumin IgG levels following 3 ovalbumin challenges, suggesting that treatments enhanced humoral immunity. Increasing YC-EHY dose also quadratically increased fecal IgA concentrations in early lactation, suggesting that 30 and $60 \mathrm{~g} / \mathrm{d}$ doses enhanced mucosal immunity. Uterine neutrophil populations were much greater in samples collected on $\mathrm{d} 7$ compared with those on $\mathrm{d}$ 42 (32.1 vs. $7.6 \pm 3.5 \%$ of cells), reflecting neutrophil infiltration immediately after calving, but no treatment effect was detected. Significant day effects were detected for mRNA of $I L-6, I L-8$, neutrophil myeloperoxi-
\end{abstract}

Received June 9, 2014.

Accepted January 15, 2015.

${ }^{1}$ Corresponding author: bbradfor@ksu.edu dase $(M P O)$, and neutrophil elastase (ELANE) in the uterine samples, reflecting greater abundance of these transcripts collected on d 7 compared with d 42. A quadratic dose effect was detected for IL-6, indicating that 30 and $60 \mathrm{~g} / \mathrm{d}$ doses decreased uterine IL-6 mRNA. The mRNA abundance of $M P O$ and ELANE was increased linearly by YC-EHY. Supplementation with YC-EHY enhanced measures of humoral and mucosal immunity and modulated uterine inflammatory signals and mammary gland health in transition dairy cows.

Key words: immunity, transition cow, uterine inflammation, yeast

\section{INTRODUCTION}

The transition from late gestation to early lactation is characterized by substantial metabolic stress and altered immune function, which may contribute to the markedly elevated incidence of health disorders in early lactation dairy cows (Goff and Horst, 1997). Developing effective nutritional strategies that could modulate the immunity of these animals is therefore critical. Yeast products derived from Saccharomyces cerevisiae have been shown to improve feed intake and milk yield in transition cows (Dann et al., 2000; Ramsing et al., 2009). Recent findings suggest yeast products may also influence immune function. Kim et al. (2011) reported that neonatal calves fed hydrolyzed yeast showed increased acute phase response, antibody production, and health scores compared with controls when challenged with live vaccines. Such responses could be attributed to improved energy status via effects on digestive function, or to activation of the immune system through sensing of yeast components in the gut and subsequent cross talk between immune cells.

One overlooked aspect of the response to yeast is the potential to influence mucosal immunity. Mucosal surfaces of the intestinal and reproductive tracts are among the most important routes of entry of microbial pathogens into the host. Epithelial cells that line mucosal surfaces are important mechanical barriers that prevent most microbes found in the environment, including commensal microbes, from entering the host 
(Kagnoff and Eckmann, 1997). A recent study (Zanello et al., 2011) reported that yeast modulated the expression of genes involved in inflammation and recruitment and activation of immune cells in porcine intestinal epithelial cells. Specifically, yeast decreased both the transcript and protein abundance of proinflammatory genes, including IL-6 and IL-8, in response to Escherichia coli exposure.

Proposed modes of action for yeast products in dairy cattle diets have expanded beyond alterations in digestive function. The objectives of the current study were to assess whether a yeast product alters (1) immunity, assessed as milk somatic cell linear score (SCLS), colostrum IgG concentrations, hematology and leukocyte differential, whole-blood bactericide of E. coli, IgG antibody production after vaccination, and $\operatorname{IgA}$ secretion from the gut mucosa; and (2) uterine inflammation, as determined by neutrophil populations and transcript abundance of inflammatory genes in uterine tissues.

\section{MATERIALS AND METHODS}

The Kansas State University Institutional Animal Care and Use Committee approved all the experimental procedures. A previous paper (Yuan et al., 2015) reported effects on feeding behavior, metabolic markers, and production outcomes.

\section{Design and Treatments}

Forty multiparous Holstein transition cows from the Kansas State University Dairy Cattle Teaching and Research Facility were used in a randomized complete block design. Cows were blocked by expected calving date (10 blocks) and randomly assigned within block to 1 of 4 treatments $21 \mathrm{~d}$ before their expected calving date. Cows remained on their respective treatments through $42 \mathrm{~d}$ postpartum. Cows received a product containing yeast culture plus enzymatically hydrolyzed yeast (YC-EHY; Celmanax, Vi-COR, Mason City, IA) at a rate of $0,30,60$, or $90 \mathrm{~g} / \mathrm{d}$. The YC-EHY was administered daily to each cow in the treatment groups by top-dressing and manually mixing the premix into the upper part of each TMR. Diets were formulated to meet or exceed NRC (2001) requirements; ingredient and nutrient composition were reported in a previous paper (Yuan et al., 2015).

\section{Management of Cows and Data Collection}

Dry cows were moved into the maternity barn approximately $1 \mathrm{wk}$ before entering the study. Cows were allowed ad libitum access to the designated treatment rations by an electronic gating system (Roughage Intake
System, Insentec B.V., Marknesse, the Netherlands). After parturition, cows were moved into a tiestall facility where they remained through $42 \mathrm{~d}$ postpartum. Dry cows were fed ad libitum twice daily (1100 and 1800 h), and lactating cows were fed twice daily (1200 and $1900 \mathrm{~h}$ ). Lactating cows were milked 3 times daily in a milking parlor. Feed intake, feeding behavior, and milk yields were recorded as described in Yuan et al. (2015). Milk samples were collected 3 consecutive days each week and were analyzed for somatic cells (SCC 500, Bentley Instruments; Heart of America DHIA, Manhattan, KS). One colostrum sample per cow was collected immediately after calving and were kept frozen at $-20^{\circ} \mathrm{C}$ until analysis of IgG concentration (Cornell Diagnostic Lab, Ithaca, NY).

Blood samples were collected on d $-21,-7,1,4,7$, 21 , and 35 relative to calving from the coccygeal vessels $1 \mathrm{~h}$ before feeding. Approximately $20 \mathrm{~mL}$ of blood was collected into 4 tubes: one 7 -mL tube containing potassium EDTA, one 3-mL tube containing potassium EDTA, one 5-mL tube containing heparin, and another 7-mL tube containing potassium oxalate with sodium fluoride as a glycolytic inhibitor (Vacutainer, Becton Dickinson, Franklin Lakes, NJ). Fecal samples were collected on $\mathrm{d} 7$ and 21 and were frozen at $-20^{\circ} \mathrm{C}$ until analysis of $\operatorname{Ig} \mathrm{A}$ concentration.

Cows were challenged (subcutaneous injection) with $1 \mathrm{mg}$ of ovalbumin (OVA; Sigma-Aldrich, St. Louis, MO) diluted in vaccine adjuvant (VET-SAP, Desert King International, San Diego, CA; $0.5 \mathrm{mg}$ of adjuvant dissolved in $1 \mathrm{~mL}$ of saline) on $\mathrm{d}-21,-7$, and $14 \mathrm{im}-$ mediately after blood sample collection $(1030 \mathrm{~h})$.

Endometrial sample collection was done using the cytobrush technique as previously described (Mendonça et al., 2014). Briefly, the procedure consisted of using a stainless steel instrument to introduce the cytobrush (Cytobrush Plus; CooperSurgical Inc., Trumball, CT) in the uterus through the vagina and cervix. While the uterus was being palpated per rectum, the instrument was guided to the body of the uterus, where the cytobrush device was exposed and rotated for the collection of endometrial sample. Slides for cytological examination were prepared by rolling the cytobrush on a glass microscope slide that was later stained with modified Wright-Giemsa stain (Protocol-Hema3, Biochemical Sciences, Swedesboro, NJ). Each slide was examined at $400 \times$ magnification to perform a differential cell count of at least 200 cells (neutrophils + endometrial cells) by a single observer. The result of this examination was reported as neutrophils as a percentage of all cells. The remaining uterine samples collected by cytobrush were transferred immediately to a 1.5-mL Eppendorf tube (Sigma-Aldrich) containing RNA preservation solution (TRIzol Reagent, Life Technologies, Carlsbad, 
CA) and frozen at $-80^{\circ} \mathrm{C}$ until RNA isolation. Samples were collected approximately on d $7(7.2 \pm 1.0 \mathrm{~d}$ across treatments; $7.2,6.8,7.3$, and $7.3 \pm 0.35 \mathrm{~d}$ for $0,30,60$, and $90 \mathrm{~g} / \mathrm{d}$, respectively) and $42(40.9 \pm 1.6 \mathrm{~d}$ across treatments; $40.9,41.4,40.2$, and $41.0 \pm 0.49 \mathrm{~d}$ for 0,30 , 60 , and $90 \mathrm{~g} / \mathrm{d}$, respectively) postpartum.

All cows were monitored daily for health status. Ketosis was recorded when urine acetoacetate exceeded 80 $\mathrm{mg} / \mathrm{dL}$ on any day or $40 \mathrm{mg} / \mathrm{dL}$ for 2 consecutive days (Ketostix; Bayer Corp. Diagnostics Division, Elkhart, IN). Other disorders or diseases were diagnosed according to the guidelines by Kelton et al. (1998).

\section{Sample Analysis}

Blood samples from the 7-mL potassium EDTA tube and the $7-\mathrm{mL}$ tube containing potassium oxalate with sodium fluoride were centrifuged at $2,000 \times g$ for 10 min at $4^{\circ} \mathrm{C}$ immediately after sample collection, and plasma was harvested and frozen at $-20^{\circ} \mathrm{C}$ until subsequent analysis of glucose, BHBA, NEFA (reported in Yuan et al., 2015), and haptoglobin concentrations. Haptoglobin was analyzed by a colorimetric method based on peroxidase activity (Cooke and Arthington, 2013). The standard curve was prepared using plasma samples from another research project (Yuan et al., 2013) with known haptoglobin concentrations, which were analyzed by ELISA (ELISA kit \#2410-7; Life Diagnostics, West Chester, PA). Absorbance was read on a spectrophotometer (Powerwave XS, Biotek Instruments, Winooski, VT), and calculations were conducted using Gen5 software (Biotek Instruments).

Blood collected from the 3-mL potassium EDTA tube was analyzed for hematology using a ProCyte hematology analyzer (Idexx Laboratories, Westbrook, ME). Whole blood collected from the 5 -mL tube containing heparin was used to test its bactericidal capacities against live cultures of environmental E. coli (ATCC \#51813) according to methods previously described (Ballou, 2012). Briefly, an overnight broth culture of the $E$. coli was diluted in nonpyrogenic $1 \times$ PBS to an approximate concentration of $25 \mathrm{cfu} / \mu \mathrm{L}$ and kept in an ice bath. Whole blood was diluted 1:1 with RPMI-1640 to a final volume of $200 \mu \mathrm{L}$. All tubes were placed in an ice bath for $5 \mathrm{~min}$. Then, $50 \mu \mathrm{L}$ of the working $E$. coli culture was added to each tube of diluted whole blood, vortexed, and incubated in a water bath at $37.5^{\circ} \mathrm{C}$ for 5 min. Following incubation, the cultures were vortexed, $50 \mu \mathrm{L}$ of each culture was pipetted and spread-plated onto tryptic soy agar plates in duplicate, and the plates were incubated overnight at $36.5^{\circ} \mathrm{C}$ before determination of the number of colony-forming units. Data are expressed as the reduction in colony-forming units for blood samples vs. controls.
Plasma samples collected on $\mathrm{d}-21,-14$, and 21 were analyzed for anti-OVA IgG using an ELISA modified from a method described by Mallard et al. (1997). All cows were analyzed for $\mathrm{d}-21$ and -14 samples. Because 9 out of the 40 cows calved more than a week earlier than expected and their $\mathrm{d}-7$ injection was not conducted, only cows that received 3 doses of OVA injection (on d $-21,-7$, and 14) were retained for the analysis of d 21 samples. Briefly, 96-well plates (Corning Costar high binding 96-well plate, Thermo Fisher Scientific Inc., Waltham, MA) were coated with $100 \mu \mathrm{L}$ of coating solution: $16.8 \mathrm{mg}$ of OVA (Sigma-Aldrich) diluted in $12 \mathrm{~mL}$ of $0.05 \mathrm{M}$ carbonate-bicarbonate buffer ( $\mathrm{pH}$ 9.4). Plates were incubated overnight at room temperature and washed 5 times with wash buffer (PBS and $0.05 \%$ Tween solution, $\mathrm{pH} 7.4)$. Plates were then blocked with $300 \mu \mathrm{L}$ of blocking buffer (4\% BSA, $5 \%$ sucrose in PBS, $0.2 \mu \mathrm{m}$ filtered) and incubated overnight at $4^{\circ} \mathrm{C}$. Plates were washed 5 times, and blank (wash buffer), diluted plasma (1:200), and pooled samples from d -21 (negative control, l:200) and 21 (positive control, 1:200) were added in duplicate. Plates were incubated for $1 \mathrm{~h}$ at room temperature and washed 5 times. Subsequently, anti-bovine IgG (Anti-Bovine IgG-peroxidase antibody produced in rabbit, SigmaAldrich) was diluted with $10 \mathrm{~m} M$ Tris buffer solution at 1:30,000, added to the plates, and incubated for $1 \mathrm{~h}$ at room temperature. Plates were then washed 5 times, and $100 \mu \mathrm{L}$ of $3,3^{\prime}, 5,5^{\prime}$-tetramethylbenzidine substrate solution (TMB solution; Thermo Fisher Scientific Inc.) was added to each well and allowed to incubate for 3 min at room temperature, followed by the addition of $100 \mu \mathrm{L}$ of stop solution (0.18 M sulfuric acid). Optical density (OD; blank-adjusted) was measured at $450 \mathrm{~nm}$ using a plate reader (PowerWaveXS, BioTek). The final OD was corrected across different plates to achieve a positive control optical density $=0.5$. For each sample, final $\mathrm{OD}=0.5 \times$ original $\mathrm{OD} \div$ positive control $\mathrm{OD}$ of that plate.

For fecal IgA analysis, the frozen fecal samples were thawed and placed immediately in ultrapurified water at a concentration of $10 \%$ (wt/vol) by weighing $1 \mathrm{~g}$ of feces and adding $9 \mathrm{~mL}$ of water. Samples were then vortexed vigorously and incubated overnight before being spun at $2,000 \times g$ for 15 min at $4^{\circ} \mathrm{C}$. The supernatants were collected and analyzed for total IgA by ELISA according to the manufacturer's instructions (Bovine IgA ELISA Quantitation Set, Bethyl Laboratories, Montgomery, TX).

Total RNA was extracted from cytobrush-collected uterine tissue using a commercial kit (RNeasy Lipid Tissue Mini Kit; Qiagen Inc., Valencia, CA) according to the manufacturer's instructions, and spectroscopy was used to quantify RNA (Nanodrop-1000, Nanodrop 
Technologies Inc., Wilmington, DE). Quality of RNA (integrity number $=6.78 \pm 1.09$ for a random subset of 16 samples) was verified with an Agilent 2100 Bioanalyzer (Agilent Technologies, Santa Clara, CA). Then, RNA was reverse-transcribed to $\mathrm{cDNA}$ and mRNA abundance of $I L-6, I L-8$, neutrophil myeloperoxidase $(M P O)$, and neutrophil elastase (ELANE) was determined by quantitative real-time (q)PCR as described (Yuan et al., 2013). Briefly, $2 \mu \mathrm{g}$ of total RNA was used as the template for the reverse transcriptase reaction using random primers (High-Capacity cDNA RT Kit; Life Technologies). Quantitative real-time PCR was performed in duplicate on 96 -well plates with $5 \%$ of the cDNA product in the presence of $200 \mathrm{n} M$ genespecific forward and reverse primers with real-time SYBR green fluorescent detection using SYBR Green Premix reagent (7500 Fast Real-Time PCR System, Life Technologies). Primers were designed (www.ncbi. nlm.nih.gov/tools/primer-blast/) using GenBank sequences (Table 1). Data were recorded and analyzed with Sequence Detector software (Life Technologies). All sample values were normalized against the geometric mean of 3 control genes, ribosomal protein subunit 9 (RPS9), RPS15, and $\beta$-actin, and relative transcript abundance was quantified by using the $2^{-\Delta \mathrm{Ct}}$ (cycle threshold, Ct) method.

\section{Data and Statistical Analysis}

One cow in the $0 \mathrm{~g} / \mathrm{d}$ group was removed from the study on d 30 postpartum due to difficulty standing up in the tiestall. Data obtained from this cow before removal were included in all analyses. Data were analyzed using mixed models with repeated measures over time. Models included the fixed effects of treatment, time, and their interaction, and the random effect of cow. Days on treatment prepartum (and 2-way interactions, including the squared term) was also evaluated as a covariate in each model, and was retained when $P$ $<0.10$ or when interactions were significant. Contrast statements were used to assess the overall effect of YCEHY (control vs. all YC-EHY doses), as well as the linear and quadratic effects of dose. If treatment by time effects were significant, slices were used to assess effects on specific days. Values were deemed outliers and omitted from analysis when Studentized residuals were $>3.0$ or $<-3.0$. After initial outlier removal, the model was repeated, and Studentized residuals $>3.5$ or $<-3.5$ were excluded. When necessary, data (including plasma haptoglobin, fecal IgA, uterine transcript abundance of $I L-6, I L-8, M P O$, and ELANE) were logtransformed before analysis to achieve normal residual distributions, and reported means and standard errors are back-transformed. Milk SCC was converted to SCLS (Shook, 1993) for analysis. Treatment effects on incidence of health disorders were evaluated by Fisher's exact test. Significance was declared at $P \leq 0.05$ and tendencies at $0.05<P \leq 0.10$.

\section{RESULTS}

No significant difference was found among groups in prepartum dietary treatment length $(18.1,18.8,17.8$, and $17.2 \pm 1.32 \mathrm{~d}$ for $0,30,60$, and $90 \mathrm{~g} / \mathrm{d}$, respectively; $P=0.86$ ). Actual calving dates ranged from 13 $\mathrm{d}$ before expected calving to $5 \mathrm{~d}$ after expected calving. Results for feed intake and milk production were reported in Yuan et al. (2015), and they were not affected $(P>0.10)$ by YC-EHY treatments.

Table 1. Primers used for quantitative real-time PCR detection of genes in the uterine tissue

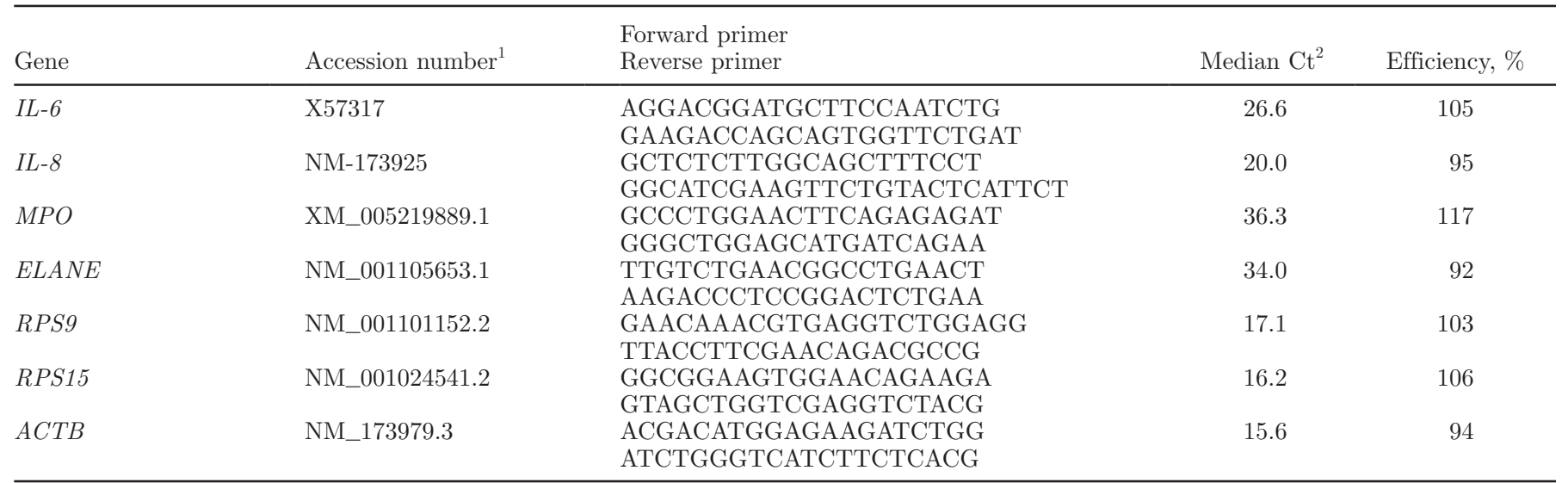

\footnotetext{
${ }^{1}$ From NCBI Entrez Nucleotide Database (http://www.ncbi.nlm.nih.gov/sites/entrez?db = nucleotide).
}

${ }^{2}$ Cycle threshold. 


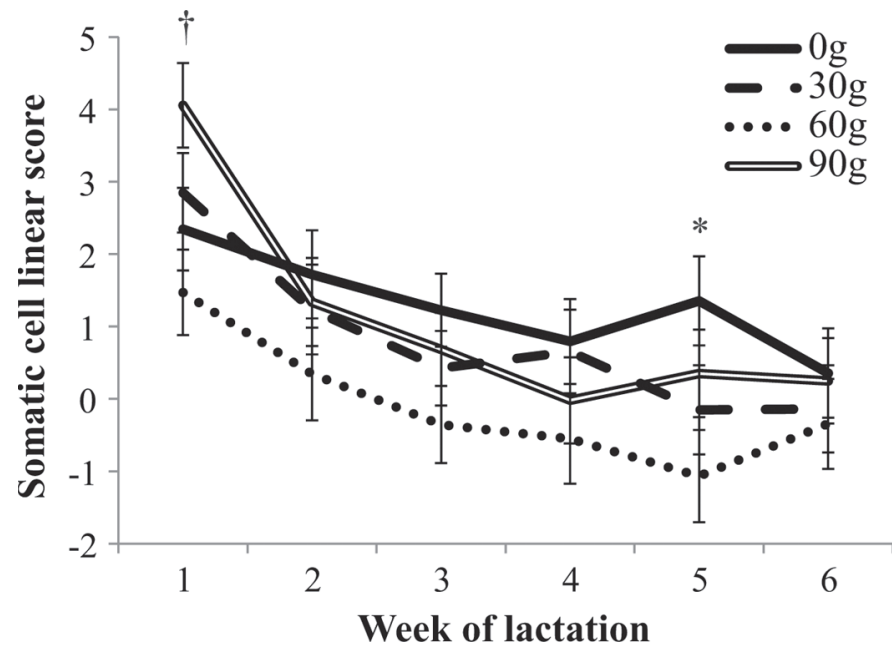

Figure 1. Milk somatic cell linear score during the experimental period. Yeast culture with enzymatically hydrolyzed yeast was supplemented at $0,30,60$, or $90 \mathrm{~g} / \mathrm{d}$ to dairy cows from $21 \mathrm{~d}$ before expected parturition to $42 \mathrm{~d}$ after parturition. There was a time effect $(P<$ $0.01)$, but no yeast product vs. control $(P=0.25)$, linear dose $(P=$ $0.53)$, or quadratic dose $(P=0.11)$ effects. There was a treatment $\times$ time $(P<0.01)$ effect, reflecting a tendency for quadratic dose effect on wk $1(P=0.08)$, and a quadratic dose effect on wk $5(P=0.02)$. An asterisk $(*)$ indicates significant differences $(P<0.05)$, a dagger $(\dagger)$ indicates tendencies $(0.05<P<0.10)$. Values are LSM \pm SEM; $\mathrm{n}=9-10$.

\section{Milk Constituents}

Concentrations of IgG in colostrum collected immediately after calving were not affected by treatments $(7.48,7.19,7.44$, and $7.89 \pm 0.42 \mathrm{~g} / \mathrm{dL}$ for $0,30,60$, and $90 \mathrm{~g} / \mathrm{d}$, respectively; $P>0.38$ for all contrasts). As shown in Figure 1, a treatment $\times$ time interaction $(P<$ 0.01 ) was observed for milk SCLS, reflecting a tendency for a quadratic dose effect on wk $1(P=0.08)$ and a quadratic dose effect on wk $5(P=0.02)$.

\section{Hematology and Leukocyte Differential}

Results of hematology and leukocyte differential analysis are shown in Table 2. No treatment effects $(P>0.10)$ were detected for erythrocyte count, hemoglobin, or leukocyte count. Hematocrit was linearly decreased $(P=0.04)$ by treatment. Platelet count was increased by YC-EHY compared with the control $(P=$ $0.04)$. Concentrations of lymphocytes, monocytes, eosinophils, and basophils were not affected $(P>0.10)$ by treatments; neutrophil concentrations were decreased $(P<0.05)$ by yeast supplementation. Time effects $(P$ $<0.01$; Table 3) were noted for erythrocyte count, hemoglobin, hematocrit, and leukocyte count. Specifically, hemoglobin, hematocrit, and erythrocyte count decreased on d 21 and 35 compared with other dates; leukocyte count increased on d 1 after parturition; platelet count decreased at the week around parturition compared with $\mathrm{d}-21$ and increased on d 21 and 35. Both concentration and proportion of neutrophils were elevated at calving; those of lymphocytes were greater at $\mathrm{d}-21$ compared with other dates, monocytes increased postpartum compared with prepartum, and eosinophils decreased postpartum compared with prepartum.

\section{Plasma Haptoglobin}

As shown in Table 2, haptoglobin was not altered by YC-EHY ( $P=0.12$, yeast product vs. control). No linear dose $(P=0.18)$, quadratic dose $(P=0.42)$, or treatment $\times$ time $(P=0.36)$ effects were detected, although the effect of time was significant (Table 3).

\section{Immune Function}

The proportion of bacteria killed by whole blood tended to increase linearly with increasing YC-EHY dose ( $P$ $=0.06$, Table 2). Neither an overall YC-EHY effect nor a quadratic dose effect was detected for whole-blood bacteriocide $(P>0.10)$. Plasma anti-OVA IgG levels increased dramatically $(P<0.01$; Figure $2 \mathrm{~A})$ after 3 OVA challenges (d 21) compared with preimmunization (d -21), as expected. Throughout the experimental period, there was a tendency for increased anti-OVA IgG in cows receiving YC-EHY $(P=0.06$; linear dose effect). A treatment $\times$ time effect $(P<0.01)$ was also detected, reflecting that YC-EHY linearly increased $(P$ $<0.01$ ) anti-OVA IgG on d 21. As shown in Figure 2B, fecal IgA concentrations were not different $(P=$ 0.61 ) between $\mathrm{d} 7$ and 21, but YC-EHY quadratically increased $(P=0.03)$ fecal IgA concentrations. The incidence of health disorders was not affected by treatments $(P>0.10$, Table 4$)$

\section{Uterine Inflammation}

Uterine neutrophil populations were much greater in samples collected on d 7 compared with d 42 (32.1 vs. $7.6 \pm 3.5 \%, P<0.01$, Figure $3 \mathrm{~A})$. There were no treatment $(P=0.53)$ or treatment $\times$ day effects $(P=$ $0.70)$. No treatment effect $(P=0.39)$ was detected for incidence of subclinical endometritis, as defined by the presence of $>10 \%$ neutrophils in uterine samples collected at d 42 (Kasimanickam et al., 2004). As shown in Table 1, the median Ct values of qPCR for $I L-6$, $I L-8, M P O$, and ELANE were 26.6, 20.0, 36.3, and 34.0 \pm 3.5 , respectively, indicating that the abundance of $M P O$ and ELANE is much less than $I L-6$ and $I L-8$. Significant $(P \leq 0.01)$ day effects for $I L-6, I L-8, M P O$, and ELANE were seen, reflecting greater abundance 
Table 2. Hematology and leukocyte differential during the experimental period ${ }^{1}$

\begin{tabular}{|c|c|c|c|c|c|c|c|c|}
\hline \multirow[b]{2}{*}{ Item } & \multicolumn{4}{|c|}{ Treatment $^{2}$} & \multirow[b]{2}{*}{ SEM } & \multicolumn{3}{|c|}{$P$-value } \\
\hline & $0 \mathrm{~g}$ & $30 \mathrm{~g}$ & $60 \mathrm{~g}$ & $90 \mathrm{~g}$ & & Yeast vs. control & Linear & Quadratic \\
\hline Plasma haptoglobin, mg/L & 520 & 272 & 248 & 244 & 135 & 0.12 & 0.18 & 0.42 \\
\hline Whole-blood bactericide, $\%$ & 14.6 & 17.7 & 24.8 & 21.2 & 8.2 & 0.78 & 0.06 & 0.62 \\
\hline \multicolumn{9}{|l|}{ Hematology } \\
\hline Leukocyte count, $10^{9}$ cells/L & 12.0 & 11.1 & 12.1 & 11.0 & 1.18 & 0.65 & 0.69 & 0.95 \\
\hline Erythrocyte count, $10^{12}$ cells $/ \mathrm{L}$ & 5.94 & 5.75 & 5.82 & 5.83 & 0.12 & 0.33 & 0.64 & 0.44 \\
\hline Hemoglobin, $\mathrm{g} / \mathrm{dL}$ & 10.3 & 10.1 & 10.3 & 9.9 & 0.15 & 0.39 & 0.20 & 0.38 \\
\hline Hematocrit, \% & 31 & 30 & 30 & 29 & 0.46 & 0.10 & 0.03 & 0.43 \\
\hline Platelet count, $10^{9}$ cells $/ \mathrm{L}$ & 203 & 254 & 266 & 273 & 22 & 0.02 & 0.03 & 0.32 \\
\hline \multicolumn{9}{|c|}{ Leukocyte concentrations, $10^{3}$ cells $/ \mu \mathrm{L}$} \\
\hline Neutrophils & 4.40 & 3.49 & 3.67 & 3.49 & 0.28 & $<0.01$ & 0.03 & 0.15 \\
\hline Lymphocytes & 5.5 & 5.4 & 6.2 & 5.5 & 0.96 & 0.90 & 0.89 & 0.76 \\
\hline Monocytes & 1.74 & 1.73 & 1.84 & 1.66 & 0.22 & 0.99 & 0.90 & 0.70 \\
\hline Eosinophils & 0.37 & 0.31 & 0.32 & 0.36 & 0.05 & 0.58 & 0.97 & 0.35 \\
\hline Basophils & 0.006 & 0.005 & 0.006 & 0.005 & 0.001 & 0.47 & 0.44 & 0.80 \\
\hline
\end{tabular}

${ }^{1}$ Values represent LSM \pm SEM for treatments across all time points $(\mathrm{n}=9-10)$. Significant time effects are shown in Table 3; treatment $\times$ time interactions were not significan for any of these variables.

${ }^{2}$ Supplementation of yeast culture with enzymatically hydrolyzed yeast (YC-EHY) to dairy cows at 0, 30, 60, or $90 \mathrm{~g} / \mathrm{d}$ from $21 \mathrm{~d}$ before expected parturition to $42 \mathrm{~d}$ after parturition.

Table 3. Acute phase, hematology, and leukocyte differential variables with significant time effects $(P<0.05)$ during the experimental period ${ }^{1}$

\begin{tabular}{|c|c|c|c|c|c|c|c|c|}
\hline \multirow[b]{2}{*}{ Item } & \multicolumn{7}{|c|}{ Day } & \multirow[b]{2}{*}{ SEM } \\
\hline & -21 & -7 & 1 & 4 & 7 & 21 & 35 & \\
\hline Plasma haptoglobin, mg/L & $230^{\mathrm{b}}$ & $234^{\mathrm{b}}$ & $1,066^{\mathrm{c}}$ & $948^{\mathrm{c}}$ & $606^{\mathrm{c}}$ & $155^{\mathrm{b}}$ & $47^{\mathrm{a}}$ & 163 \\
\hline \multicolumn{9}{|l|}{ Hematology } \\
\hline Erythrocyte count, $10^{12}$ cells $/ \mathrm{L}$ & $6.10^{\mathrm{d}}$ & $6.07^{\mathrm{cd}}$ & $6.17^{\mathrm{d}}$ & $5.92^{\mathrm{c}}$ & $5.75^{\mathrm{b}}$ & $5.48^{\mathrm{a}}$ & $5.37^{\mathrm{a}}$ & 0.08 \\
\hline Hemoglobin, $\mathrm{g} / \mathrm{dL}$ & $10.7^{\mathrm{d}}$ & $10.6^{\mathrm{d}}$ & $10.8^{\mathrm{d}}$ & $10.3^{\mathrm{c}}$ & $10.1^{\mathrm{b}}$ & $9.5^{\mathrm{a}}$ & $9.2^{\mathrm{a}}$ & 0.13 \\
\hline Hematocrit, \% & $31.6^{\mathrm{d}}$ & $31.8^{\text {de }}$ & $32.7^{\mathrm{e}}$ & $31.3^{\mathrm{d}}$ & $29.9^{\mathrm{c}}$ & $27.1^{\mathrm{b}}$ & $26.0^{\mathrm{a}}$ & 0.41 \\
\hline Platelet count, $10^{9}$ cells $/ \mathrm{L}$ & $244^{\mathrm{b}}$ & $176^{\mathrm{a}}$ & $214^{\mathrm{ab}}$ & $186^{\mathrm{a}}$ & $208^{\mathrm{ab}}$ & $350^{\mathrm{c}}$ & $366^{\mathrm{c}}$ & 21 \\
\hline \multicolumn{9}{|c|}{ Leukocyte concentrations, $10^{3}$ cells $/ \mu \mathrm{L}$} \\
\hline Neutrophils & $3.39^{\mathrm{ab}}$ & $4.14^{\mathrm{c}}$ & $4.94^{\mathrm{d}}$ & $2.78^{\mathrm{a}}$ & $3.19^{\mathrm{ab}}$ & $3.69^{\mathrm{bc}}$ & $4.19^{c}$ & 0.24 \\
\hline Monocytes & $1.13^{\mathrm{a}}$ & $1.42^{\mathrm{a}}$ & $1.87^{\mathrm{b}}$ & $2.10^{\mathrm{b}}$ & $1.84^{\mathrm{b}}$ & $1.95^{\mathrm{b}}$ & $1.92^{\mathrm{b}}$ & 0.15 \\
\hline Lymphocytes & $6.22^{\mathrm{c}}$ & $5.53^{\mathrm{ab}}$ & $5.45^{\mathrm{ab}}$ & $5.27^{\mathrm{a}}$ & $5.68^{\mathrm{b}}$ & $5.63^{\mathrm{ab}}$ & $5.72^{\mathrm{ab}}$ & 0.51 \\
\hline Eosinophils & $0.62^{\mathrm{d}}$ & $0.60^{\mathrm{d}}$ & $0.32^{\mathrm{c}}$ & $0.24^{\mathrm{b}}$ & $0.15^{\mathrm{a}}$ & $0.20^{\mathrm{ab}}$ & $0.27^{\mathrm{bc}}$ & 0.04 \\
\hline
\end{tabular}

$\bigcirc \quad{ }^{\mathrm{a}-\mathrm{d}}$ Values within rows that do not share a common superscript are significantly different $(P<0.05)$. Pairwise differences were evaluated by the PDIFF option when the overall ef$œ$ fect of time was significant.

Z Values are least squares means \pm SEM, $\mathrm{n}=39-40$ 
Table 4. Incidence of health disorders during the experimental period

\begin{tabular}{lcccc}
\hline & \multicolumn{4}{c}{ Treatment $^{2}$} \\
\cline { 2 - 5 } Disorder $^{1}$ & $0 \mathrm{~g}$ & $30 \mathrm{~g}$ & $60 \mathrm{~g}$ & $90 \mathrm{~g}$ \\
\hline Ketosis & 1 & 3 & 1 & 1 \\
Retained placenta & 1 & 1 & 3 & 1 \\
Metritis & 3 & 1 & 3 & 1 \\
Subclinical endometritis & 1 & 3 & 2 & 2 \\
Clinical mastitis & 2 & 1 & 0 & 1 \\
Displaced abomasum & 0 & 1 & 0 & 1 \\
$\geq 1$ event & 5 & 4 & 4 & 4 \\
\hline
\end{tabular}

${ }^{1}$ Ketosis was recorded when the urine ketone dipstick test (Ketostix; Bayer Corp. Diagnostics Division, Elkhart, IN) detected acetoacetate $>80 \mathrm{mg} / \mathrm{dL}$ on any day or $>40 \mathrm{mg} / \mathrm{dL}$ for 2 consecutive days. Other health disorders were diagnosed according to the guidelines by Kelton et al. (1998).

${ }^{2}$ There were no treatment effects ( $P>0.10$ by Fisher's Exact Test) on the incidence of any disorders. Yeast product was supplemented at 0 , 30,60 , or $90 \mathrm{~g} / \mathrm{d}$ to transition dairy cows from $21 \mathrm{~d}$ before expected calving to $42 \mathrm{~d}$ after calving.

of these transcripts in uterine tissues collected on $\mathrm{d} 7$ compared with d 42 (Figures 3B - 3E). Specifically, compared with d 42 , the abundance of uterine $I L-6$ and $I L-8$ was over 25 -fold greater on $\mathrm{d} 7$, and that of $M P O$ and ELANE was over 2-fold greater. Interestingly, a quadratic dose effect $(P=0.01)$ was noted for $I L-6$, indicating that 30 and $60 \mathrm{~g} / \mathrm{d}$ doses decreased uterine $I L-6$ mRNA abundance. No treatment effects $(P>0.10)$ were detected for $I L-8$. The abundance of MPO $(P=0.05$, linear dose effect) and ELANE ( $P$ $=0.02$, linear dose effect) was increased by YC-EHY supplementation.

\section{DISCUSSION}

A growing body of evidence suggests that yeast components may influence immune function (Kim et al., 2011; Zanello et al., 2011). The immune system is complex, however, and no single measure is likely to fully reflect immune status in vivo. We therefore approached this question with a battery of measures to gauge immunity-related responses in the uterus, mammary gland, and circulation of cows during the transition to lactation.

After the transition period, one major hurdle for the dairy cow is the return to estrus and breeding. We proposed to explore the effect of YC-EHY on neutrophil populations and expression of inflammatory mediators in the uterus at 2 key time points: $\mathrm{d} 7$ and 42 postpartum. At least some bacteria are commonly present in the uterus in the first week after calving (LeBlanc et al., 2011), and neutrophils are needed to clear pathogens and facilitate the involution of reproductive tissues (Challis et al., 2009). By d 42 postpartum, cows with a sufficient immune response will have cleared the
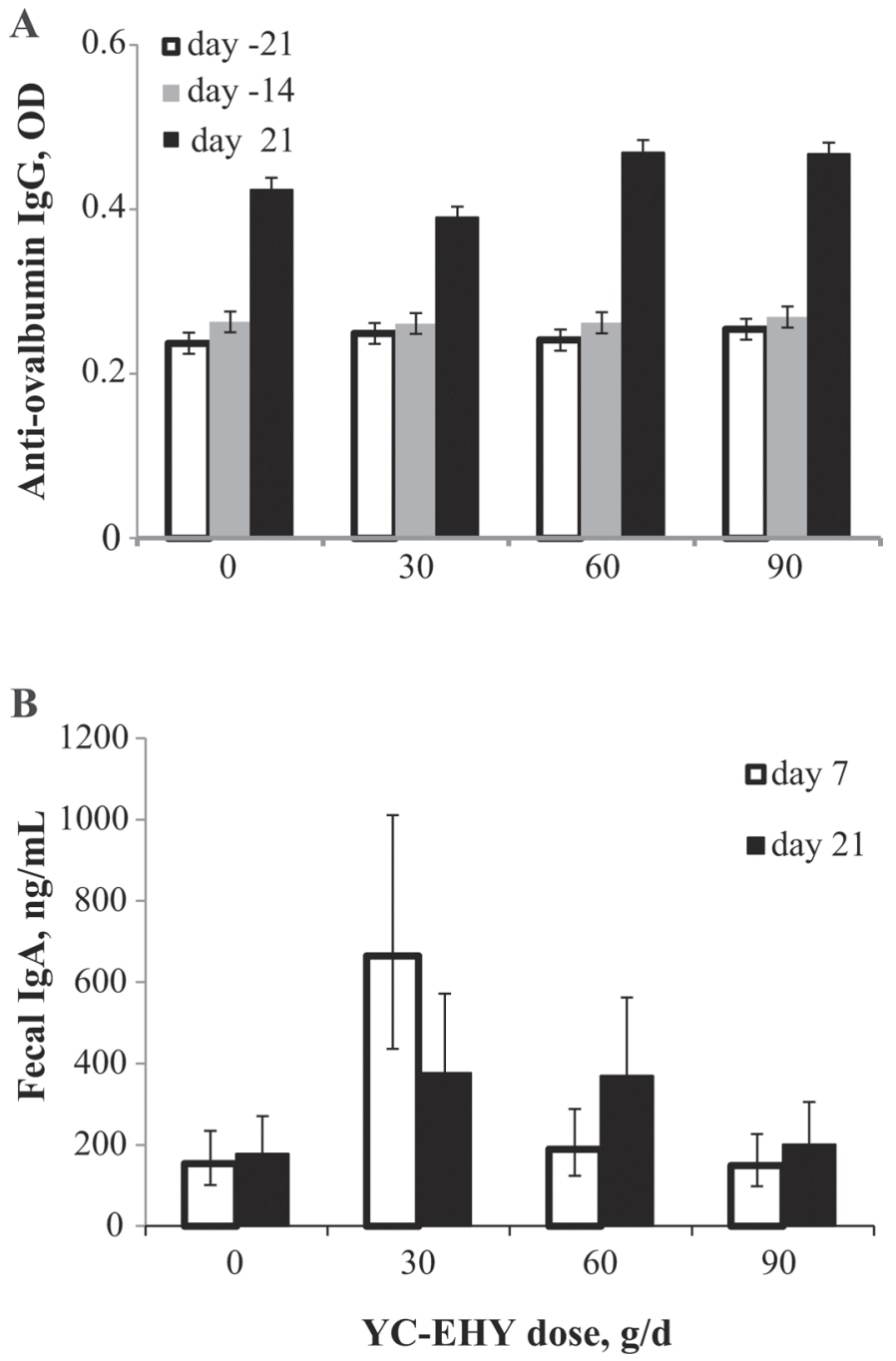

Figure 2. Antibody responses to yeast culture with enzymatically hydrolyzed yeast (YC-EHY) supplemented to dairy cows at $0,30,60$, or $90 \mathrm{~g} / \mathrm{d}$ from $21 \mathrm{~d}$ before expected parturition to $42 \mathrm{~d}$ after parturition. (A) Plasma concentrations of anti-ovalbumin IgG collected on d $-21,-14$, and 21 relative to calving. Cows were challenged on $\mathrm{d}-21$, -7 , and 14 with ovalbumin. There was a tendency for linear dose effect $(P=0.06)$ and a day effect $(P<0.01)$, but no yeast product vs. control $(P=0.41)$ or quadratic dose $(P=0.50)$ effects. There was a treatment $\times$ day $(P<0.01)$ effect, reflecting that yeast product linearly increased $(P<0.01)$ anti-ovalbumin $\operatorname{IgG}$ on $\mathrm{d} 21$. (B) Concentrations of IgA in fecal samples collected on d 7 and 21 relative to calving. There was a significant quadratic dose effect $(P=0.03)$, but no yeast product vs. control $(P=0.16)$, linear dose $(P=0.73)$, day $(P=0.61)$, or treatment $\times$ day $(P=0.42)$ effects. Values are least squares means $\pm \mathrm{SEM} ; \mathrm{n}=10 . \mathrm{OD}=$ optical density.

bacteria, and neutrophil populations and expression of inflammatory mediators should be minimal, but other cows will still be fighting persistent infections (LeBlanc et al., 2011), which may greatly impair fertility (Bell and Roberts, 2007). We did not find treatment effects for uterine neutrophil populations, but across treatments there were much greater numbers of neutrophils in samples collected on d 7 compared with d 42 . 
A

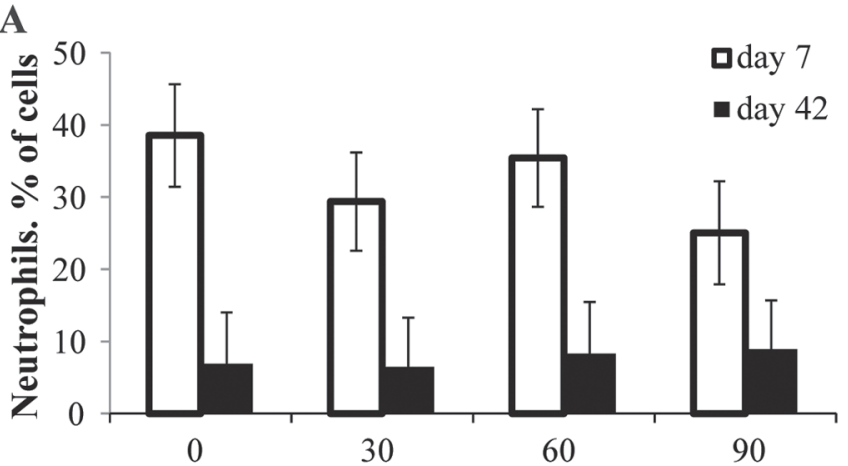

C

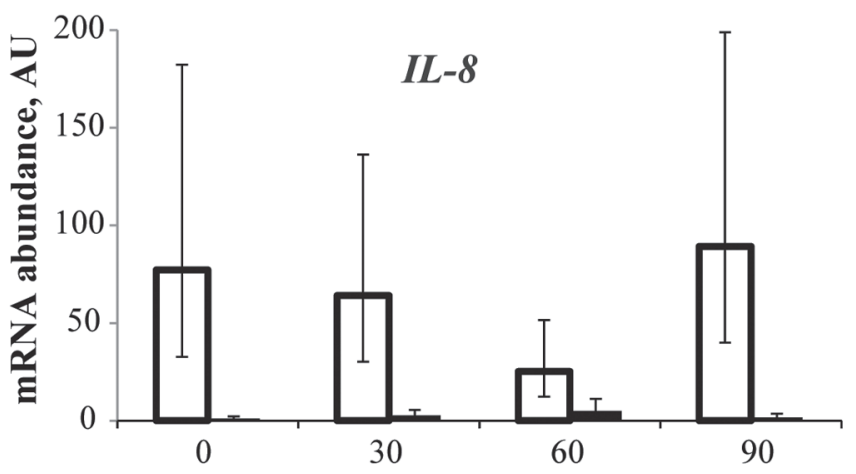

$\mathbf{E}$

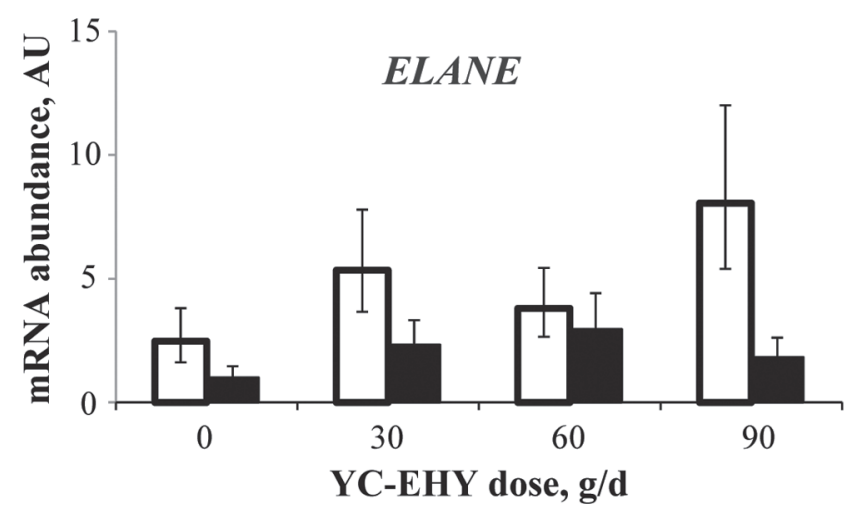

B 200

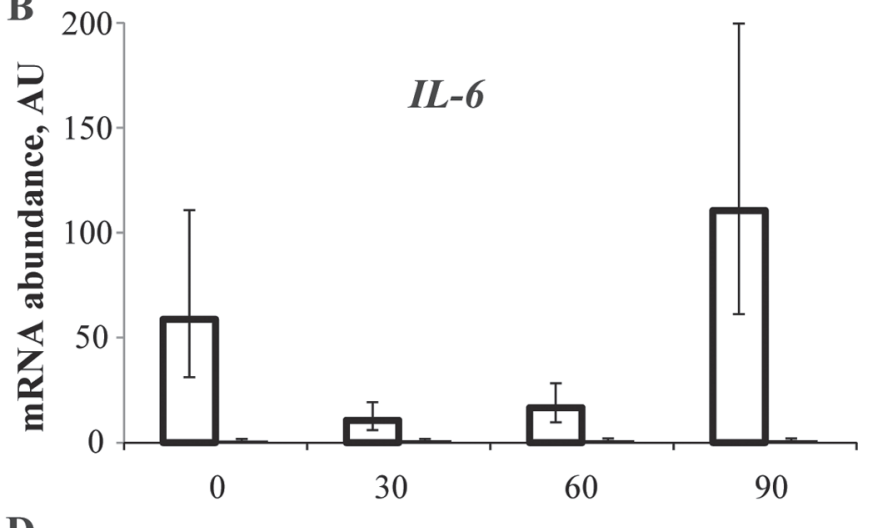

D

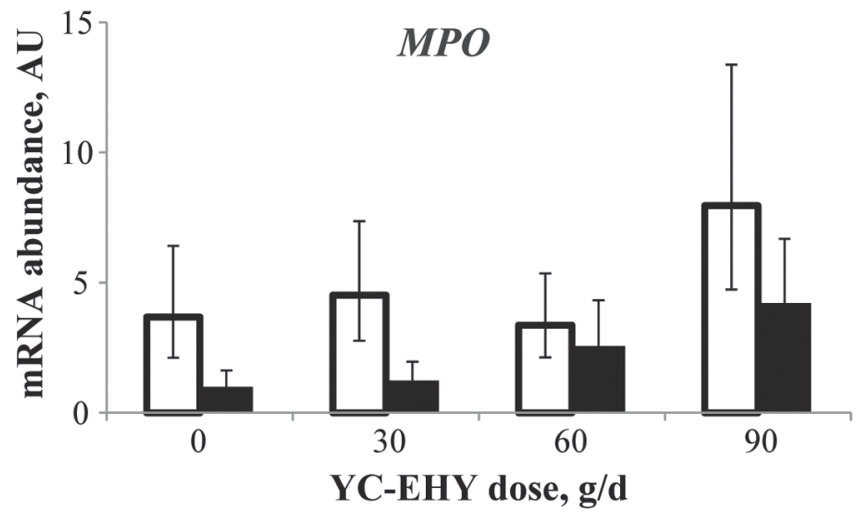

Figure 3. Uterine cytobrush sample measures during supplementation of yeast culture with enzymatically hydrolyzed yeast (YC-EHY) to dairy cows at $0,30,60$, or $90 \mathrm{~g} / \mathrm{d}$ from $21 \mathrm{~d}$ before expected parturition to $42 \mathrm{~d}$ after parturition. (A) Neutrophil populations as a proportion of total collected cells were affected by day $(P<0.01)$, but no yeast product vs. control $(P=0.53)$, linear dose $(P=0.57)$, quadratic dose $(P=$ $0.99)$, or treatment $\times$ day $(P=0.70)$ effects were detected. (B) Transcript abundance of $I L-6$ : there were day $(P<0.001)$ and quadratic dose $(P=0.01)$ effects, but no yeast product vs. control $(P=0.38)$, linear dose $(P=0.37)$, or treatment $\times$ day $(P=0.28)$ effects. $(\mathrm{C})$ Transcript abundance of $I L$ - 8 : there was a day effect $(P<0.01)$, but no yeast product vs. control $(P=0.60)$, linear dose $(P=0.71)$, quadratic dose $(P=$ $0.77)$, or treatment $\times$ day $(P=0.35)$ effects. (D) Transcript abundance of neutrophil myeloperoxidase $(M P O)$ : there were day $(P=0.01)$ and linear dose $(P=0.05)$ effects, but no yeast product vs. control $(P=0.20)$, quadratic dose $(P=0.54)$, or treatment $\times$ day $(P=0.61)$ effects. (E) Transcript abundance of neutrophil elastase $(E L A N E)$ : there were day $(P<0.01)$, yeast product vs. control $(P<0.01)$, and linear dose $(P=0.02)$ effects, but no quadratic dose $(P=0.17)$ or treatment $\times$ day $(P=0.55)$ effects. Values are least squares means \pm SEM; $\mathrm{n}=8-10$.

We evaluated transcript abundance of $I L-6$ and $I L-8$ as indicators of uterine inflammation. As important proinflammatory cytokines, IL-6 and IL-8 are expressed in the uterine tissues of postpartum cows, and the abundance of these transcripts was linked to the incidence of subclinical endometritis (Ghasemi et al., 2012). We found that the abundance of $I L-6$ and $I L-8$ was more than 25 -fold greater in samples collected on d 7 compared with d 42, consistent with greater inflammation in the uterus immediately after calving. To 
assess neutrophil activation status, we also evaluated the mRNA abundance of 2 neutrophil-derived enzymes, neutrophil myeloperoxidase and neutrophil elastase. Myeloperoxidase is a lysosomal protein stored in neutrophil azurophilic granules and plays a key role in the microbicidal activity of neutrophils (Klebanoff, 2005). As a serine protease, neutrophil elastase is responsible for degradation of proteins during phagocytosis as well as degradation of connective tissue during an inflammatory process (Helmig et al., 2002). The abundance of $M P O$ and ELANE was more than 2-fold greater on d 7 compared with d 42 , which is consistent with the finding that neutrophil populations in uterine samples were greater on $\mathrm{d} 7$ than on $\mathrm{d} 42$.

Some treatment effects on the abundance of these inflammation-related transcripts were detected. Supplementation of YC-EHY at 30 and $60 \mathrm{~g} / \mathrm{d}$, but not $90 \mathrm{~g} / \mathrm{d}$, decreased uterine $I L-6$ mRNA abundance, whereas the abundance of MPO and ELANE was linearly increased by treatments. Although several lines of evidence (Jensen et al., 2008; Kim et al., 2011; Zanello et al., 2011) indicate that yeast or yeast culture may modulate inflammation, no previous studies have evaluated the effects of dietary yeast products on the inflammatory profiles of reproductive tissues. Although YC-EHY exerted inconsistent effects on different uterine inflammatory signals and the implications are unclear, our findings nevertheless indicate that yeast components can modulate inflammation and perhaps reproductive function.

Both concentrations and relative proportions of neutrophils in blood were elevated at calving, which is consistent with the fact that cows typically experience neutrophilia at parturition (Burton and Erskine, 2003). Despite increased neutrophil numbers in early lactation, their bactericidal function is often impaired, which is associated with increased risk of infection during the transition period (Burton and Erskine, 2003). Interestingly, YC-EHY supplementation decreased blood concentrations of neutrophils but tended to enhance bacteriocidal capacity of whole blood, indicating a modulatory effect on immune cells. Considering the observed increase in neutrophil-specific transcripts in uterine tissue on $\mathrm{d} 7$, it is possible that the blood neutrophil response is a result of enhanced neutrophil migration into tissues with YC-EHY supplementation.

Although there were no treatment effects, hemoglobin, hematocrit, and erythrocyte count decreased on d 21 and 35 compared with other dates; it is possible that these changes resulted from the increased plasma volume associated with increased milk output as lactation proceeds (Burton et al., 1992). Platelet count decreased in the week around parturition compared with $\mathrm{d}-21$ and increased on $\mathrm{d} 21$ and 35; this response is likely associated with parturition-associated blood loss and clotting. We also found that YC-EHY increased platelet count, which is consistent with the finding that hydrolyzed yeast supplementation dramatically increased platelet count in neonatal calves challenged with vaccine (Kim et al., 2011). Because of their abundance and their ability to rapidly release cytokines and other immune mediators, platelets play a central role in modulating immune function ( $\mathrm{Li}$ et al., 2012; Jenne et al., 2013). Recent evidence suggests that platelets can directly modulate neutrophil function and clear pathogens (Jenne et al., 2013). The temporal changes in platelet counts in our study seem consistent with the changes of neutrophil function in the transition period (Kehrli et al., 1989). Given the importance of platelets in immune modulation, their role in the altered immune function of transition cows is worthy of additional investigation.

In addition to high prevalence of uterine infections, mastitis is also a common disease in early lactation cows (LeBlanc et al., 2011). We found a tendency for a quadratic dose effect for SCLS on wk 1 and a quadratic dose effect on wk 5 of lactation, reflecting decreased SCLS by 30 and $60 \mathrm{~g} / \mathrm{d}$ doses. These results suggest that YC-EHY modulated mammary gland health in early lactation cows. Similarly, Nocek et al. (2011) reported that supplementation of YC-EHY at $28 \mathrm{~g} / \mathrm{cow}$ per day throughout the first $14 \mathrm{wk}$ of lactation decreased SCC and cases of clinical mastitis. Zaworski et al. (2014) reported that yeast product supplementation at $56 \mathrm{~g} /$ cow per day during the transition period decreased SCC in early lactation. Interestingly, the finding that $90 \mathrm{~g} / \mathrm{d}$ increased SCLS on the first week of lactation suggests that this dose might have exceeded the optimal level of supplementation, possibly promoting an adverse inflammatory response in the mammary gland.

To assess humoral immune response, we measured antibody production in response to repeated challenges with OVA. As expected, in response to a third challenge after 2 prepartum challenges, anti-OVA IgG increased dramatically. At that time point, YC-EHY linearly increased levels of anti-OVA IgG, suggesting that YCEHY supplementation enhanced humoral immunity. It should be noted that although the increase by YC-EHY is statistically significant, it is unclear whether these small differences in antibody titer would be biologically meaningful. Mallard et al. (1997) partitioned transition cows into 3 groups based on antibody response (i.e., high, low, and nonresponders) to OVA challenge and found that cows with the highest antibody response also tended $(P \leq 0.10)$ to have the highest response to $E$. coli challenge at parturition and had the lowest incidence of diseases, particularly mastitis. The stimulatory effects of yeast products on humoral immunity 
have been observed across different species. Franklin et al. (2005) reported that supplementation of yeast cell wall components, mannan-oligosaccharides, to cows during the last $3 \mathrm{wk}$ of the dry period enhanced their antibody response to rotavirus and tended to enhance the subsequent transfer of rotavirus antibodies to calves. Muthusamy et al. (2011) reported that feeding hydrolyzed yeast and yeast cell wall components increased the blood antibody titer against Newcastle virus following vaccination in broilers. Another key constituent of yeast cell walls, $\beta$-glucan, has also been shown to enhance the defense against infections in rodent models (Samuelsen et al., 2014).

Mucosal immune responses are the first line of defense because most pathogenic agents enter the host via mucosal surfaces, and IgA secreted by the gut plays crucial roles in this mucosal defense by entrapping microorganisms and preventing the adherence of pathogens to the mucosal surface (Neutra and Kozlowski, 2006). Secreted $\operatorname{IgA}$ are therefore critical for maintaining a stable gut microbiota (Suzuki et al., 2004). In our study, YC-EHY quadratically increased fecal IgA concentrations, suggesting that 30 and $60 \mathrm{~g} / \mathrm{d}$ doses enhanced at least one component of mucosal immune function. Several studies have used fecal IgA concentration as an indicator of mucosal immunity. Gurzell et al. (2013) observed that fish oil supplementation in mice improved mucosal immune function by increasing secretory fecal IgA and the numbers and function of B cells in gut-associated lymphoid tissues. Scholtens et al. (2008) reported that prebiotic oligosaccharide supplementation in milk formula increased fecal IgA concentrations in infants; together with the altered composition of intestinal microbiota in response to treatment, the authors concluded that increased IgA suggests a positive effect of prebiotic on mucosal immunity. Viljanen et al. (2005) found probiotic supplementation increased fecal IgA and decreased tumor necrosis factor- $\alpha$ concentrations in infants with food allergic atopic eczema and proposed that this increased IgA indicates an attempt of the host to protect the gut from allergic food antigens, whereas decreased tumor necrosis factor- $\alpha$ suggests that probiotics decreased inflammation in the gut. Previous research has demonstrated several possible mechanisms of the immunostimulatory effects of yeast components. For example, mannan-oligosaccharides can act as antiadhesive agents and prevent colonization of pathogens in the intestinal tract by providing alternative adhesion sites to intestinal bacteria (Ganner and Schatzmayr, 2012). Furthermore, yeast components have been reported to offer structural benefits to the intestine by increasing villus height and number of goblet cells (Solis de los Santos et al., 2007; Muthusamy et al., 2011), which are responsible for the secretion of intestinal mucus.
Increased mucus would, in turn, help lubricate intestinal surfaces, trap and neutralize bacteria, and protect epithelial cells (Johansson et al., 2013), all of which could contribute to intestinal immune health.

Given the number and diversity of immune measures influenced by YC-EHY, it seems reasonable to assert that YC-EHY modulates immune system function. The mechanisms underlying these effects are less clear. The well-documented effect of $\beta$-glucans on immune cell activity, mediated by dectin-1 (Kankkunen et al., 2010), may be part of the story. Though $\beta$-glucans are not efficiently absorbed, gut-associated lymphoid tissues can have substantial influence on circulating immune cells (Izcue et al., 2006), providing a mechanism whereby signals at the mucosal surface can broadly affect the function of leukocytes that migrate to damaged or infected tissues (Onderdonk et al., 1992). Whether such effects increase the ability of a cow to fight off and recover from an infection such as mastitis or metritis is not entirely clear, although measures of humoral immunity were associated with mastitis recovery (Mallard et al., 1997). A direct assessment of responses to infection may provide more definitive evidence as to whether dietary yeast (dependent on dose and duration of administration) improves immunity in cattle, as it does in rodent models (Samuelsen et al., 2014).

\section{ACKNOWLEDGMENTS}

This manuscript is contribution no. 14-354-J from the Kansas Agricultural Experiment Station (Manhattan). We thank Vi-COR Inc. (Mason City, IA) for providing funding to support this study. We thank Michael Scheffel, Nicole Eberhart, Sam Kennett-Vachon, Blake Madsen, Erin Atsaves, Jacob Dreiling, and Fabian Vargas at Kansas State University for animal care and technical assistance. RNA integrity analysis was provided by the Molecular Biology Core supported by Kansas State University College of Veterinary Medicine (Manhattan).

\section{REFERENCES}

Ballou, M. A. 2012. Inflammation: Role in the etiology and pathophysiology of clinical mastitis in dairy cows. J. Anim. Sci. 90:14661478 .

Bell, M. J., and D. J. Roberts. 2007. The impact of uterine infection on a dairy cow's performance. Theriogenology 68:1074-1079.

Burton, J. L., and R. J. Erskine. 2003. Immunity and mastitis: Some new ideas for an old disease. Vet. Clin. North Am. Food Anim. Pract. 19:1-45.

Burton, J. L., B. W. McBride, B. W. Kennedy, J. H. Burton, T. H Elsasser, and B. Woodward. 1992. Hematological profiles in dairy cows treated with recombinant bovine somatotropin. J. Anim. Sci. 70:1488-1495.

Challis, J. R., C. J. Lockwood, L. Myatt, J. E. Norman, J. F. Strauss, and F. Petraglia. 2009. Inflammation and pregnancy. Reprod. Sci. $16: 206-215$. 
Cooke, R. F., and J. D. Arthington. 2013. Concentrations of haptoglobin in bovine plasma determined by ELISA or a colorimetric method based on peroxidase activity. J. Anim. Physiol. Anim. Nutr. (Berl.) 97:531-536.

Dann, H. M., J. K. Drackley, G. C. McCoy, M. F. Hutjems, and J. E. Garrett. 2000. Effects of yeast culture (Saccharomyces cerevisiae) on prepartum intake and postpartum intake and milk production of Jersey cows. J. Dairy Sci. 83:123-127.

Franklin, S. T., M. C. Newman, K. E. Newman, and K. I. Meek 2005. Immune parameters of dry cows fed mannan oligosaccharide and subsequent transfer of immunity to calves. J. Dairy Sci. $88: 766-775$.

Ganner, A., and G. Schatzmayr. 2012. Capability of yeast derivatives to adhere enteropathogenic bacteria and to modulate cells of the innate immune system. Appl. Microbiol. Biotechnol. 95:289-297.

Ghasemi, F., P. Gonzalez-Cano, P. J. Griebel, and C. Palmer. 2012. Proinflammatory cytokine gene expression in endometrial cytobrush samples harvested from cows with and without subclinical endometritis. Theriogenology 78:1538-1547.

Goff, J. P., and R. L. Horst. 1997. Physiological changes at parturition and their relationship to metabolic disorders. J. Dairy Sci. $80: 1260-1268$

Gurzell, E. A., H. Teague, M. Harris, J. Clinthorne, S. R. Shaikh, and J. I. Fenton. 2013. DHA-enriched fish oil targets B cell lipid microdomains and enhances ex vivo and in vivo B cell function. J. Leukoc. Biol. 93:463-470.

Helmig, B. R., R. Romero, J. Espinoza, T. Chaiworapongsa, E. Bujold, R. Gomez, K. Ohlsson, and N. Uldbjerg. 2002. Neutrophil elastase and secretory leukocyte protease inhibitor in prelabor rupture of membranes, parturition and intra-amniotic infection. J. Matern. Fetal Neonatal Med. 12:237-246.

Izcue, A., J. L. Coombes, and F. Powrie. 2006. Regulatory T cells suppress systemic and mucosal immune activation to control intestinal inflammation. Immunol. Rev. 212:256-271.

Jenne, C. N., R. Urrutia, and P. Kubes. 2013. Platelets: Bridging hemostasis, inflammation, and immunity. Int. J. Lab. Hematol. $35: 254-261$.

Jensen, G. S., K. M. Patterson, and I. Yoon. 2008. Yeast culture has anti-inflammatory effects and specifically activates NK cells. Comp. Immunol. Microbiol. Infect. Dis. 31:487-500.

Johansson, M. E., H. Sjövall, and G. C. Hansson. 2013. The gastrointestinal mucus system in health and disease. Nat. Rev. Gastroenterol. Hepatol. 10:352-361. http://dx.doi.org/10.1038/ nrgastro.2013.35.

Kagnoff, M. F., and L. Eckmann. 1997. Epithelial cells as sensors for microbial infection. J. Clin. Invest. 100:6-10.

Kankkunen, P., L. Teirila, J. Rintahaka, H. Alenius, H. Wolff, and S. Matikainen. 2010. (1,3)-beta-glucans activate both dectin-1 and NLRP3 inflammasome in human macrophages. J. Immunol. 184:6335-6342.

Kasimanickam, R., T. F. Duffield, R. A. Foster, C. J. Gartley, K. E. Leslie, J. S. Walton, and W. H. Johnson. 2004. Endometrial cytology and ultrasonography for the detection of subclinical endometritis in postpartum dairy cows. Theriogenology 62:9-23.

Kehrli, M. E., Jr., B. J. Nonnecke, and J. A. Roth. 1989. Alterations in bovine neutrophil function during the periparturient period. Am. J. Vet. Res. 50:207-214

Kelton, D. F., K. D. Lissemore, and R. E. Martin. 1998. Recommendations for recording and calculating the incidence of selected clinical diseases of dairy cattle. J. Dairy Sci. 81:2502-2509.

Kim, M. H., J. K. Seo, C. H. Yun, S. J. Kang, J. Y. Ko, and J. K. Ha. 2011. Effects of hydrolyzed yeast supplementation in calf starter on immune responses to vaccine challenge in neonatal calves. Animal 5:953-960.

Klebanoff, S. J. 2005. Myeloperoxidase: Friend and foe. J. Leukoc. Biol. 77:598-625.

LeBlanc, S. J., T. Osawa, and J. Dubuc. 2011. Reproductive tract defense and disease in postpartum dairy cows. Theriogenology $76: 1610-1618$

Li, C., J. Li, Y. Li, S. Lang, I. Yougbare, G. Zhu, P. Chen, and H. Ni. 2012. Crosstalk between platelets and the immune system: Old systems with new discoveries. Adv. Hematol. 2012:384685.
Mallard, B. A., L. C. Wagter, M. J. Ireland, and J. C. Dekkers. 1997. Effects of growth hormone, insulin-like growth factor-I, and cortisol on periparturient antibody response profiles of dairy cattle. Vet. Immunol. Immunopathol. 60:61-76.

Mendonça, L. G., C. C. Abade, E. M. da Silva, N. B. Litherland, L. B. Hansen, W. P. Hansen, and R. C. Chebel. 2014. Comparison of peripartum metabolic status and postpartum health of Holstein and Montbéliarde-sired crossbred dairy cows. J. Dairy Sci $97: 805-818$.

Muthusamy, N., S. Haldar, T. K. Ghosh, and M. R. Bedford. 2011. Effects of hydrolysed Saccharomyces cerevisiae yeast and yeast cell wall components on live performance, intestinal histo-morphology and humoral immune response of broilers. Br. Poult. Sci. 52:694703.

Neutra, M. R., and P. A. Kozlowski. 2006. Mucosal vaccines: The promise and the challenge. Nat. Rev. Immunol. 6:148-158.

Nocek, J. E., M. G. Holt, and J. Oppy. 2011. Effects of supplementation with yeast culture and enzymatically hydrolyzed yeast on performance of early lactation dairy cattle. J. Dairy Sci. 94:40464056 .

NRC. 2001. Nutrient Requirements of Dairy Cattle. 7th rev. ed. Natl. Acad. Sci., Washington, DC.

Onderdonk, A. B., R. L. Cisneros, P. Hinkson, and G. Ostroff. 1992. Anti-infective effect of poly-beta 1-6-glucotriosyl-beta 1-3-glucopyranose glucan in vivo. Infect. Immun. 60:1642-1647.

Ramsing, E. M., J. A. Davidson, P. D. French, I. Yoon, M. Keller, and H. Peters-Fleckenstein. 2009. Effect of yeast culture on peripartum intake and milk production of primiparous and multiparous Holstein cows. Prof. Anim. Sci. 25:487-495.

Samuelsen, A. B., J. Schrezenmeir, and S. H. Knutsen. 2014. Effects of orally administered yeast-derived beta-glucans: A review. Mol. Nutr. Food Res. 58:183-193.

Scholtens, P. A., P. Alliet, M. Raes, M. S. Alles, H. Kroes, G. Boehm, L. M. Knippels, J. Knol, and Y. Vandenplas. 2008. Fecal secretory immunoglobulin $\mathrm{A}$ is increased in healthy infants who receive a formula with short-chain galacto-oligosaccharides and long-chain fructo-oligosaccharides. J. Nutr. 138:1141-1147.

Shook, G. E. 1993. Genetic improvement of mastitis through selection on somatic cell count. Vet. Clin. North Am. Food Anim. Pract. 9:563-581.

Solis de los Santos, F., A. M. Donoghue, M. B. Farnel, G. R. Huff, W. E. Huff, and D. J. Donoghue. 2007. Gastrointestinal maturation is accelerated in turkey poults supplemented with a mannan-oligosaccharide yeast extract (Alphamune). Poult. Sci. 86:921-930.

Suzuki, K. B. Meek, Y. Doi, M. Muramatsu, T. Chiba, T. Honjo, and S. Fagarasan. 2004. Aberrant expansion of segmented filamentous bacteria in IgA deficient gut. Proc. Natl. Acad. Sci. USA 101:1981-1986.

Viljanen, M., M. Kuitunen, T. Haahtela, K. Juntunen-Backman, R. Korpela, and E. Savilahti. 2005. Probiotic effects on faecal inflammatory markers and on faecal IgA in food allergic atopic eczema/ dermatitis syndrome infants. Pediatr. Allergy Immunol. 16:65-71.

Yuan, K., J. K. Farney, L. K. Mamedova, L. M. Sordillo, and B. J. Bradford. 2013. TNF $\alpha$ altered inflammatory responses, impaired health and productivity, but did not affect glucose or lipid metabolism in early-lactation dairy cows. PLoS ONE 8:e80316.

Yuan, K., T. Liang, M. B. Muckey, L. G. Mendonça, L. E. Hulbert, C. C. Elrod, and B. J. Bradford. 2015. Yeast product supplementation modulated feeding behavior and metabolism in transition dairy cows. J. Dairy Sci. 98:532-540.

Zanello, G., M. Berri, J. Dupont, P.-Y. Sizaret, R. D'Inca, H. Salmon, and F. Meurens. 2011. Saccharomyces cerevisiae modulates immune gene expressions and inhibits ETEC-mediated ERK1/2 and p38 signaling pathways in intestinal epithelial cells. PLoS ONE 6:e18573.

Zaworski, E. M., C. M. Shriver-Munsch, N. A. Fadden, W. K. Sanchez, I. Yoon, and G. Bobe. 2014. Effects of feeding various dosages of Saccharomyces cerevisiae fermentation product in transition dairy cows. J. Dairy Sci. 97:3081-3098. 